\title{
Progress Toward Overset-Grid Moving Body Capability for USM3D Unstructured Flow Solver
}

\author{
Mohagna J. Pandya* \\ Swales Aerospace, Inc, Hampton, Virginia 23681, USA \\ Neal T. Frink ${ }^{\dagger}$ \\ NASA Langley Research Center, Hampton, Virginia 23681, USA \\ and \\ Ralph W. Noack ${ }^{*}$ \\ University of Alabama at Birmingham, Alabama, 92647, USA
}

\begin{abstract}
A static and dynamic Chimera overset-grid capability is added to an established NASA tetrahedral unstructured parallel Navier-Stokes flow solver, USM3D. Modifications to the solver primarily consist of a few strategic calls to the Donor interpolation Receptor Transaction library (DiRTlib) to facilitate communication of solution information between various grids. The assembly of multiple overlapping grids into a single-zone composite grid is performed by the Structured, Unstructured and Generalized Grid AssembleR (SUGGAR) code. Several test cases are presented to verify the implementation, assess overset-grid solution accuracy and convergence relative to single-grid solutions, and demonstrate the prescribed relative grid motion capability.
\end{abstract}

\section{Introduction}

The Naval Air Systems Command (NAVAIR) and NASA Langley Research Center (LaRC) have engaged in a 3-year cooperative effort to develop a computational modeling and simulation suite capable of handling air vehicle stability and control under the title of "Integrated Simulation of Air Vehicle Performance, Stability and Control for Test and Evaluation." The joint NAVAIR/NASA commitment provides a substantial augmentation for improving the capabilities of an existing state-of-the-art computational system, known as TetrUSS [1], to enhance its ability to solve important problems encountered during flight tests. While the NAVAIR focus is on military aircraft, NASA is maintaining a parallel focus supporting civilian aircraft and launch vehicle applications.

This paper addresses the need for rapid and accurate aerodynamic computation of complex geometric components having relative movement or motion. The timeliness of computational support for flight test and evaluation is primarily driven by how quickly a computational grid can be constructed about the configuration and modified for its variations. For example, the computation of a flight maneuver for a military aircraft often requires an array of scheduled flap deflections. Each deflection can require a time consuming regeneration of the grid. Similarly, military flight-testing often involves the evaluation of multiple store/carriage configurations and their separation properties. Multistage launch vehicles are typically augmented with strap-on boosters that separate from the vehicle at supersonic speeds during assent. The high-fidelity modeling of a helicopter rotor can require the computation of rotating blades above the fuselage. Thus, the range of aerodynamic applications with components in relative motion is significant.

The Chimera overset-grid approach [2]-[4] is an established technique for treating multi-component grids in relative motion. The primary innovation of the overset method is the accommodation of "holes" within grids [5], which are those points that are outside the domain of interest and hence are excluded from the computations. The

\footnotetext{
* Senior Member AIAA. Senior Research Engineer.

${ }^{\dagger}$ Associate Fellow, AIAA. Senior Research Engineer, Configuration Aerodynamics Branch, Mail Stop 499.

* Senior Member, AIAA. CFD On-site Lead for the PET program at the Army Research Laboratory Major Shared Resource Center, Aberdeen, Maryland.
} 
holes and their boundaries within a grid allow the solution from one overlapping grid to be coupled to the solutions on other grids, thus forming a single composite grid and solution. The grid points adjacent to the holes become boundary points, which are termed as receptor, fringe, or intergrid boundary points. The marking of holes and the surrounding fringe boundaries form the first phase of an overset grid assembly process. The boundary values required by the flow-field solution at the fringe points are obtained by interpolating the solution from appropriate donor cells using information from other grids that overlap the region. Utilization of this technology has been highly successful for computing relative motion applications such as store and stage separation problems [6],[7], and highfidelity rotorcraft applications [8].

The predominant implementation of overset methodology over the past decade has been in structured-grid flow solvers. The primary disadvantage to this approach is the difficulty in generating structured, hexahedral grids around complex geometries - a process that can often require weeks to months of labor. In recent years, the overset-grid technology has begun to migrate into unstructured-grid flow solvers [9]-[11]. The prime advantage of unstructuredgrids is the relative ease of generating tetrahedral grids about complex geometries, which can take hours or days. Thus, unstructured overset-grid codes offer the hope of more rapid response to flow problems with multi-component motion.

The implementation of the overset-grid technique into existing structured and unstructured flow solvers typically requires extensive and tedious code modifications. The modifications enable highly integrated functions of hole cutting, surface-grid assembly, near-body grid assembly, and off-body grid assembly. Since most of the overset functions are straightforward and essentially duplicated among flow solvers, Noack developed a powerful set of tools, called Donor interpolation Receptor Transaction library (DiRTlib) [12], and the Structured, Unstructured and Generalized Grid AssembleR (SUGGAR) [13]-[15] code, to facilitate the rapid implementation of overset-grid capability into most structured and unstructured flow solvers. Experience has shown that this capability can be installed into most flow solvers within days. Thus, the present authors have collaborated to install and test the DiRTlib overset capability into the TetrUSS/USM3D tetrahedral flow solver [16]-[18].

The present paper describes the implementation of the DiRTlib functional libraries into the USM3D code to create an overset-grid capability in an established unstructured flow solver. The work is presently in the early verification stage, which will be demonstrated by comparing both static and dynamic overset-grid solutions with corresponding single-grid solutions. For the static case, overset-grid solutions for a supersonic ramp and for a full $3 \mathrm{D}$ wing/store configuration will be presented. We will also show dynamic overset moving-grid solutions on the NACA 0012 airfoil in pitch oscillation.

\section{Description of Methodology}

The NASA Tetrahedral Unstructured Software System (TetrUSS) [1] is a complete flow analysis system that has been widely used in industry and government since 1991. Its strength is derived from harnessing various component technologies into a user-friendly system to provide rapid, higher-order analysis and design capability to the applied aerodynamicist. TetrUSS is a loosely integrated, user-friendly software that consists of a geometry setup tool GridTool [19], a tetrahedral grid generator VGRID [20],[21], a flow solver USM3D [16]-[18], and post-processing visualization and data extraction utilities. The system maintains sufficient flexibility that other researchers can utilize various components, such as grid generation, to support their codes as well. The extensions addressed in this paper pertain to the USM3D flow solver and will be described below.

\section{A. USM3D Flow Solver}

USM3D is a tetrahedral cell-centered, finite volume Euler and Navier-Stokes (N-S) flow solver. Inviscid flux quantities are computed across each cell face using Roe's [22] flux-difference splitting (FDS). Spatial discretization is accomplished by a novel reconstruction process [23], that is based on an analytical formulation for computing solution gradients within tetrahedral cells. The solution is advanced in time by an implicit backward-Euler timestepping scheme [24] with local time-stepping convergence acceleration for steady-state problems.

USM3D has several closure models for capturing flow turbulence effects. First is the Spalart-Allmaras (SA) oneequation model [25], which can be coupled with a wall function boundary condition to reduce the number of cells in the sublayer region of the boundary layer. However, the wall function is typically used only when extensive curvature-based separation is not expected in a flow simulation. The second model is the two-equation k- $\varepsilon$ turbulence model [26],[27]. The third model is the Menter SST two-equation model [28]. These turbulence models have undergone rigorous testing on propulsion afterbody flows in reference [29]. Two nonlinear Algebraic Reynolds Stress Models (ARSM) by Girimaji [30], and Shih/Zhu/Lumley [31], have recently been installed in USM3D and are undergoing verification testing. 
USM3D supports an array of useful boundary conditions (BC's). It contains the standard BC's of flow tangency or no-slip on solid surfaces, characteristic inflow/outflow for subsonic boundaries, and freestream inflow and extrapolation outflow for supersonic flow. Some additional special BC's are also available for jet exhaust and intake, a propeller/rotor actuator disk model, and passive porosity [32].

The most recent enhancements to USM3D are second-order time accuracy, Detached Eddy Simulation, and dynamic grid motion [18]. The second-order accuracy in time and grid motion capability was prerequisite to the dynamic overset-grid modification.

USM3D runs on massively parallel computers and clusters of personal computers (PC's). A grid-partitioning file is quickly generated during a preprocessing step with a customized version of the Metis code [33]. A global restart file is generated and saved during and after each run. Thus, the user may readily change the number of processors from one restart run to the next if desired.

\section{B. Implementation of Overset-Grid Capability}

The approach for the present work is to construct a single composite grid from several overlapping grids using the SUGGAR grid assembly code. SUGGAR is capable of handling structured, unstructured, and general polyhedral unstructured grids. It performs the hole cutting using an octree-based Cartesian approximation of the geometry. It uses a standard neighbor walk search for locating the donors for a fringe point. Initial guess for the donor search is based on the octree. For cell-centered flow solvers, a donor member list is constructed of the donor cell containing the fringe locations and the cells sharing a face with the donor cell. SUGGAR writes domain connectivity information to a file that identifies hole cells (i.e. cells to be excluded from the computation), fringe cells at intergrid boundary, and donor members and interpolation weights.

The fringe-cell marking algorithm inside SUGGAR required some custom treatment to interface properly with the USM3D flow solver. The standard fringe-layer marking in SUGGAR is based on face-centric neighbors as shown in Fig. 1(a). This approach is consistent with the cell-centered flow solvers relying on a least-square approach for the flow gradient computation. However, USM3D uses a novel analytical formula for the solution gradient that utilizes cell-centered and nodal quantities for the second-order spatial accuracy. The nodal quantities are derived from a weighted averaging of the surrounding cell-centered information. Therefore, SUGGAR has been modified as shown in Fig. 1(b) to provide an extended layer of fringe cells to prevent contamination of the inviscid flux inside the field cells that are adjacent to the fringe cells. For Navier-Stokes solutions, SUGGAR has been further modified with a subroutine to satisfy special data-ordering requirements within USM3D that impacted the minimum distance function of the turbulence model for multiple overlapping grids.

Overset-grid capability is implemented in USM3D by leveraging a generalized library known as DiRTlib that encapsulates the basic overset functions related to the transfer of solution quantities across component grids. DiRTlib is a solver-neutral library that significantly expedites the addition of overset grid capability into existing flow solvers. It makes calls to a few solver-specific functions to interface DiRTlib with solver data in the computer memory. Two basic interface functions allow DiRTlib to "get" data from solver memory for use in donor interpolations and "put" data into solver memory for use at the fringe locations. DiRTlib also provides functions to read domain connectivity information and use it to fill a solver-provided "iblank" array with an integer flag that identifies fringe or hole cells to the flow solver. The flow solver has been augmented with a new function that uses this iblank information to modify the linear equation solver such that no updates to the solution are produced at the hole and fringe cells. Subsequently, the flow properties within the hole cells are set to an average of their neighboring cell values. This treatment of the hole cells continuously updates the freestream-initialized solution and therefore guards against an abrupt jump in the solution characteristics, should any of the hole cells become a field cell after moving the body. Next, the flow solver makes a few strategic calls to the DiRTlib functions to transmit updated solution quantities from the donor cells to the fringe cells. The entire process is repeated at each iteration/sub-iteration of the steady/time-accurate solution cycle. For the moving-body simulations, the flow solver uses additional DiRTlib functions to access the body transformations generated by SUGGAR and use them to reposition the grid associated with a moving body.

Some challenges were encountered during the implementation of the overset capability into USM3D. For example, consistency issues related to a code-specific internal reassignment of the cell partitions for parallel processing had to be addressed. Also, modifications were made inside the flow solver to transfer solution variables from the hole/fringe cells at the inter-partition boundary to cells in adjacent partitions. Several approaches for donor interpolation weights were investigated to address the robustness and accuracy issues encountered during computations of a test case. These approaches will be illustrated in the following section.

The current overset-grid framework has been developed in USM3D for the static and prescribed-motion capability. Figure 2 outlines the procedure employed for the prescribed-motion cases. A simple Python script controls the motion. At each physical time step, the flow solver signals the motion-controller to calculate and 
provide new body positions (transformations) to the grid assembly code SUGGAR. The flow solver with the help of DiRTlib internally moves the newly assembled grid and performs a series of iterates to attain a converged solution for the current time step. This sequence is repeated for the user-prescribed number of time steps. Synchronization and serialization of three distinct processes, namely, SUGGAR, USM3D and motion-controlling script is accomplished by named pipes, known as First-In-First-Out (FIFO) files, which are shown in smaller rectangles in Fig. 2. SUGGAR waits until the body transformations are read from the FIFO file, Fifo_SUGGAR.inp, before performing the grids assembly with the new body positions. Similarly, execution of USM3D will wait until SUGGAR writes a signal to the Fifo_SUGGAR.out file signifying the completion of grid-assembly.

\section{Results and Discussion}

This section presents the initial verification results for the implementation of overset-grid capability into USM3D. Static, non-moving grid results are compared between single- and overset-grids for a supersonic ramp and a full 3D wing/store configuration. These test cases will assess the impact of overset-boundary effects on solution quality and convergence. A dynamic overset moving-grid solution is presented for the NACA 0012 airfoil in pitch oscillation.

\section{A. Static Overset Grids}

\section{Supersonic ramp}

While not a good practice, the placement of overlapping grids in the high-gradient flow regions such as shocks is often unavoidable for realistic problems such as full air-vehicle transonic/supersonic store/stage separation computations. Hence, some induced solution error is expected from the donor-receptor interpolation. An inviscid supersonic ramp test case is selected to assess the impact of the present implementation of DiRTLib within USM3D on strong shock traversing an overset region.

The test case is a 15-degree ramp that produces an oblique shock with Mach 2.5 inflow. The computational domain, shown in Fig. 3, consists of an inflow ground plane from $x=-0.5$ to 0.0 and a 15-degree ramp from $x=0.0$ to 1.0 spanning between two side planes at $\mathrm{y}=+/-0.25$. The upper boundary terminates at $\mathrm{z}=1.5$.

Both single (non-overset) and overset (dual) grids were generated for the domain using the VGRID code. The surface triangulation for the single grid is shown in Fig. 3 where the full-domain volume contains 1,127,529 isotropic tetrahedral cells. The VGRID spacing parameters were applied to yield approximate cell size of 0.01 $(\Delta \mathrm{s}=0.01)$ on the ramp surface, $\Delta \mathrm{s}=0.03$ on the inflow plane, and $\Delta \mathrm{s}=0.02$ on the aft upper boundary.

Similar overset grids were constructed on upper and lower regions of the global domain. The lower overset grid was constructed $(608,427$ cells) by eliminating the upper region above $\mathrm{z}=0.6$. Similarly, the upper overset grid was generated $(793,778$ cells) by eliminating the lower domain below $\mathrm{z}=0.4$. When combined, the two independent grids share an overlap region of $\Delta \mathrm{z}=0.2$ through which the oblique shock will pass. It should be noted that the same distribution of cell size from the single grid was applied to both of the overset grids. Thus, the cells in the overlap region are of similar size, but not identical. Figure 4 portrays the side-plane triangulation for the single and overset grids.

Inviscid flow solutions were computed on the single and overset grids. Boundary conditions consisted of Mach 2.5 freestream inflow, extrapolation outflow, tangent-flow floor and ramp, symmetry-plane walls, and characteristic inflow/outflow upper boundary. An encouraging comparison of single- vs. overset-grid pressure contours on a midspan cutting plane $(\mathrm{y}=0)$ is shown in Fig. 5. A close inspection suggests a minimal impact of the solution interpolations on the pressure through the overset region. A comparison in Fig. 6 of the longitudinal pressure distribution on the surface and on a line passing midway through the overset region from inflow- to outflow-plane further confirms a nominal impact of the overset grid on the shock solution. The post-shock pressure ratio in Fig. 6(a) is in good agreement with the exact value of 2.4675 [34]. Convergence of the normalized solution residual error, as shown in Fig. 7, is similar between single- and overset-grids. It should be noted that the blanked-out cells are not included in the residual summation for the overset grid.

\section{Wing/store configuration}

The Eglin wing/pylon/store (WPS) configuration [35],[36] provides a simple, yet challenging three-dimensional test case for applying an overset grid method due to the close proximity of two bodies in transonic flow. The configuration consists of a 45-degree swept clipped delta wing with a constant NACA 64A010 symmetrical airfoil. The wing has a root chord of $15 \mathrm{in}$,, a semispan of $13 \mathrm{in}$., and a taper ratio of 0.134 . The pylon is located at the midspan station and has a cross section that is characterized by a flat plate closed at the leading and trailing edges by a symmetrical ogive. Suspended 0.07 inches beneath the pylon by a separate support sting is a 1-inch diameter cylindrical store with an ogive nose and four fins. 
An extensive database has been reported in Ref. [35] for two Mach numbers of 0.95 and 1.20, including steadystate pressure distributions on all the components, as well as transient force and moment data on the store. For this verification study, the computations were performed at Mach 0.95 for the selected store positions shown in Table 1 . These store positions are representative of the baseline carriage position (Carriage), an intermediate position (Near), and the farthest position (Far). The corresponding test run numbers from the experimental data are provided in the table for reference. The translations $\Delta x, \Delta y$, and $\Delta z$ are referenced to the store center of gravity (c.g.) that is located 2.79 store diameters aft of its nose along the cylindrical axis. The orientation of the coordinate system in the tables is $x$ positive downstream, $y$ positive spanwise, and $z$ positive up. The rotations $\Psi, \Theta$, and $\Phi$ are positive with yaw outboard, pitch nose up, and roll outboard, respectively. The store rotations were obtained by standard Euler transformations about the store c.g.

Table 1 Store position data for $M a c h=0.95$ cases

\begin{tabular}{lllcccccc}
\hline \hline & Store & \multicolumn{3}{c}{ Store translations } & & \multicolumn{3}{c}{ Store rotations } \\
\cline { 3 - 4 } \cline { 7 - 9 } & Position & & & & & yaw & pitch & roll \\
& & $\Delta x$, in & $\Delta y$, in & $\Delta z$, in & & $\Psi$, deg & $\Theta$, deg & $\Phi$, deg \\
\hline Run 1 & Carriage & 0.000 & 0.000 & 0.000 & & 0.00 & 0.00 & 0.00 \\
Run 8 & Near & 0.126 & -0.102 & -1.068 & & 4.95 & 5.20 & 2.80 \\
Run 10 & Far & 0.468 & -0.186 & -2.388 & & 12.01 & 2.27 & 6.30 \\
\hline \hline
\end{tabular}

Tetrahedral viscous grids were constructed for the half-span WPS geometry with three store positions as seen in Fig. 8 for both single- and overset-computational domains. The single grid had 6,812,784 cells, whereas for the overset domains, the wing-alone grid had 5,386,532 cells, and the store-alone grid had 1,194,301 cells. During the first attempt at assembling the grids for the store in carriage position, over 40,000 orphan cells were encountered in the region around pylon and store fins. Therefore, an additional 11 embedded interface grids, shown in Fig. 9, with a total of 2,799,264 cells, were constructed and placed in this region to reduce the number of orphan cells. With the introduction of these interface grids, the number of orphan points is reduced to approximately 45 cells. The total number of cells in the final composite overset grid is $9,380,097$. The use of interface grids is common with overset structured-grid methods and is equally important for unstructured grids due to the hyperbolic nature of the generated grids.

Steady-state Navier-Stokes flow solutions were computed for the three cases in Table 1 at Mach $0.95, \alpha=0$ deg, and $\mathrm{Re}=2.56 \times 10^{6}$ per foot. The flow was assumed fully turbulent with a nominal boundary layer spacing of $\mathrm{y}^{+}=2$ and 36 tetrahedra across the boundary layer. The Spalart-Allmaras (SA) model [37] was used for modeling turbulence.

Our initial approach for the donor weight interpolations within an overset grid solution was based on the standard least square weights. However, overset grid solutions based on these unlimited least square weights rapidly encountered nonphysical flow state and exhibited a lack of robustness, for all the three positions of a store. Therefore, SUGGAR was modified to compute the donor weights based on an inverse distance approach. This approach was successful in stabilizing the solutions. However, a fully converged steady-state solution overset grid solution based on this approach was in substantial disagreement with the corresponding single grid solution, for the carriage position of store. This discrepancy was attributed to a less-than second-order-accurate characteristic of the inverse distance weights. Next, a strictly second-order approach based on laplacian weights [23] was investigated. The laplacian weights retained a desired robustness and also improved the solution accuracy as compared to the inverse distance weights. However, laplacian weight solution still differed from the single grid solution. For example, store carriage position integrated normal force coefficient values corresponding to the single grid, overset grids inverse distance weights, and overset grids laplacian weights were $0.554,0.468$, and 0.504 , respectively.

Based on an observed solution inaccuracy from other donor weight interpolations, an effort was made to further investigate a lack of robustness of the least square weights. To this end, solution variables were initialized with converged values corresponding to the inverse distance weights, rather than initializing them with the freestream values and a solution was attempted using least square weights. This solution with better initialization also failed eventually, although it progressed farther toward a converged-state than a previously attempted solution that used a freestream initialization. Notably though, the normal force coefficient value was observed to be climbing up from a low inverse distance value to a corresponding single grid value. Based on these observations, a limiter was applied on the interpolated solution variables to keep their values within the range of the donor cell values. The DiRTlib was modified to force this monotonic behavior on an interpolated solution. With his modification, a converged and accurate least square weights solution could be obtained successfully, despite initializing the solution variables with a freestream values. A converged normal force coefficient value of 0.558 for this solution matched reasonably well 
with the corresponding single grid value. Therefore, a limited least square weights were used for all subsequent solutions that are reported herein for this test case.

A typical solution history plot is shown in Fig. 10 to verify the similar convergence behavior of the overset- and single-grid solutions. Figures 11 and 12 show the effect of the overset boundary on field pressure coefficient isobars in two cross-sectional planes. In Fig. 11, the plane cuts the streamwise axis through the store, fins, pylon, and wing. In Fig. 12, a field cut is made across the spanwise axis through the wing, pylon, and store geometries. Note the smooth transfer of pressures across the overset boundary denoted by the rectangles in the left images of Figs. 11 and 12. A further comparison between the overset and single grid isobars in these figures reveals a minimal impact of the overset boundaries on the solution.

A quantitative assessment of solution accuracy is made in Figs. 13 and 14 using surface pressure distributions. Figure 13 portrays the longitudinal distribution of pressure coefficient on the upper and lower wing surfaces at a spanwise station of 1.2 store diameters inboard of the pylon for the three store positions from Table 1 . The primary result is that the overset and single grid solutions are in very close agreement. Both solutions are in good agreement with the data of Ref. [35] with the exception that the transonic shocks are in general 10- to 20-percent aft of the experimental values. Additional studies of grid resolution, turbulence model, and flow transition are underway to resolve those differences. The focus of the present work is to verify the implementation of the overset grid capability. Figure 14 portrays similar longitudinal distributions of pressure coefficient along upper and lower extent of the store body for the three positions. Note once again the impact of the overset grid is negligible compared to the single grid.

In addition to the pressure comparisons shown above, force and moment integrations were computed on the store for all flow solutions. The results are summarized in Table 2 in terms of $C_{N}, C_{Y}$, and $C_{A}$ for normal, side, and axial forces, and $C_{m}, C_{n}$, and $C_{l}$ for pitching, yawing, and rolling moment, respectively. These coefficients are based on the store cross-sectional area, $S_{r e f}=0.785 \mathrm{in}^{2}$, diameter, $D_{\text {ref }}=1.0 \mathrm{in}$., and c.g. located at $2.79 \mathrm{in}$. aft of the nose on the store centerline. As seen in the comparisons, agreement between overset- and single-grid solutions is good, although some differences are present. These results represent the best achieved after an extensive effort to determine a suitable intergrid interpolation scheme, extent of hole cutting, and interface grid placement strategy. The experimental data from the steady-state carriage position are included in Table 2 for the general assessment of the overall solution.

Table 2 Comparison of force and moment coefficients on the store

\begin{tabular}{|c|c|c|c|c|c|c|c|}
\hline & \multicolumn{3}{|c|}{ Store Carriage } & \multirow{2}{*}{\multicolumn{2}{|c|}{$\begin{array}{c}\text { Store Near } \\
\text { USM3D }\end{array}$}} & \multirow{2}{*}{\multicolumn{2}{|c|}{$\begin{array}{l}\text { Store Far } \\
\text { USM3D }\end{array}$}} \\
\hline & \multicolumn{2}{|c|}{ USM3D } & \multirow{2}{*}{ Data } & & & & \\
\hline & Overset & Single & & Overset & Single & Overset & Single \\
\hline$C_{N}$ & 0.558 & 0.554 & 0.644 & 0.824 & 0.837 & 0.243 & 0.242 \\
\hline$C_{Y}$ & -1.001 & -1.002 & -0.954 & 0.192 & 0.211 & 1.069 & 1.093 \\
\hline$C_{A}$ & 0.811 & 0.807 & 0.901 & 0.908 & 0.926 & 1.179 & 1.197 \\
\hline$C_{m}$ & -1.526 & -1.490 & -1.430 & -1.297 & -1.342 & -0.903 & -0.926 \\
\hline$C_{n}$ & 1.750 & 1.747 & 1.520 & 0.453 & 0.450 & -0.380 & -0.400 \\
\hline$C_{l}$ & 0.094 & 0.097 & 0.100 & 0.223 & 0.231 & 0.370 & 0.379 \\
\hline
\end{tabular}

\section{B. Dynamic Overset Grids}

\section{Oscillating NACA 0012 Airfoil}

The NACA 0012 airfoil has been experimentally tested in ramp and oscillatory pitch motions about the quarterchord point at Aircraft Research Association Ltd, England. The results from the tests conducted at several freestream and pitch conditions have been reported in an AGARD report by Landon [38]. The unsteady flow prediction capability of USM3D has been assessed using the AGARD CT case 1 that corresponds to the test at a freestream Mach number of 0.6 and chord Reynolds number of $4.8 \times 10^{6}$. The angle-of-attack variation is prescribed as follows:

$$
\alpha(\mathrm{t})=\alpha_{\text {mean }}+\alpha_{\text {ampl }} \sin (2 \pi f t) \text { where } \alpha_{\text {mean }}=2.89^{\circ}, \alpha_{\text {ampl }}=2.41^{\circ} \text { and } f=50.34 \mathrm{~Hz} \text {. }
$$

For this problem, a quasi 3-D simulation of a 2-D problem has been performed and a narrow rectangular wing made up of NACA 0012 airfoil cross-sections between two endwalls has been considered. The wing has a chord of

$$
6
$$


unit length and span equivalent to 4-percent of the chord. As illustrated in Fig. 15, two independent tetrahedral grids were generated for the airfoil and the outer box domain, and then combined through the SUGGAR code to form a single composite grid. The airfoil grid has 174,049 cells, the outer box grid has 201,972 cells, and the combined grid has 376,021 cells. The viscous spacing has approximately 25 points ( 75 tetrahedra) across the boundary layer and average spacing of the first layer of nodes from the wing surface is $5.3 \times 10^{-6}$ yielding $y^{+}=1$. Fig. 15 shows that the red airfoil grid is embedded in the blue outer-box grid. The SUGGAR code has cut a hole in the box grid as evident by the missing blue cells around the airfoil. These cells have not been removed, but are blanked out within the equation solver. The grid-to-grid interpolations occur along fringe cells near the edge of the hole and near the outer boundary of the red airfoil grid. As described in Fig. 2, the motion controller drives the sinusoidal oscillation of the airfoil grid and the SUGGAR code recomputes the donor/receptor cell interpolation stencils for each movement.

Flow solutions were computed with 800 timesteps per pitch cycle using the Spalart-Allmaras turbulence model. Two snapshots of the off-body pressure contours corresponding to the overset-grid solution at the maximum and minimum angles of oscillation are presented in Fig. 16. Note the smoothness of the contours across the inner overset hole boundary (blue) and the outer overset boundary (red). A comparison of the lift and pitching moment coefficient hysteresis loops in Fig. 17 shows a minimal effect of the overset boundary relative to a single-grid solution.

\section{Concluding Remarks}

The implementation of Chimera overset grid capability into the NASA USM3D tetrahedral cell-centered unstructured flow solver is well underway. The approach is to leverage emerging overset-grid libraries, called DiRTlib, and grid assembly tool, SUGGAR, to provide the least intrusive changes to the flow solver. Initial verification studies have established the correctness of grid-to-grid communication and the solution accuracy for both static and dynamic overset tetrahedral grids

A number of remaining issues are currently being addressed. An assessment of the dynamic motion capability for the wing/pylon/store configuration involving the "dropping" of the store along a prescribed-motion path is underway. More efficient strategies for reducing the number of orphan cells encountered during grid assembly on tetrahedral grids are also being explored. A parallel version of the grid assembly code SUGGAR is being investigated for the faster turnaround of dynamic motion cases. The USM3D/DiRTlib/SUGGAR system is being ported to NASA and DoD high-performance computers to enable application to larger problems.

Several important items have yet to be addressed. Many more validation studies are needed to establish guidelines for the correct application of this new overset-grid capability. Also, the issue of collar-grids in oversetboundary regions has not been broached at this point, although we have several ideas for addressing it. Finally, the integration with a six degree-of-freedom motion-capability will be explored in the future.

\section{Acknowledgements}

The authors wish to thank the following organizations and individuals for their generous support toward this work. The Department of Defense (DoD) High Performance Computing Modernization Office (HPCMO) is providing funding support through the Common High Performance Computing Software Support Initiative (CHSSI) and under the Programming Environment and Training (PET) activities through Mississippi State University under terms of Agreement No. GS04T01BFC0060. The opinions expressed herein are those of the authors and do not necessarily reflect the views of the DoD or Mississippi State University. Dr. Dave Findley, head of the Advanced Aerodynamics Branch at NAVAIR, manages the Collaborative Simulation and Testing (CST) portfolio under CHSSI. Dr. James Chung of NAVAIR manages the "Integrated Simulation of Air Vehicle Performance, Stability and Control for Test and Evaluation" subproject under the CST portfolio. Dr. Robert M. Hall of NASA Langley provides coordination with the Computational Methods for Stability and Control (COMSAC) subproject. The authors would also like to thank Dr. Robert Nichols of University of Alabama at Birmingham for many fruitful discussions related to the current work.

\section{References}

[1] Frink, N.T., Pirzadeh, S.Z., Parikh, P.C., and Pandya, M.J., "The NASA Tetrahedral Unstructured Software System (TetrUSS)," The Aeronautical Journal, Vol.104, No. 1040, October 2000, pp. 491-499.

[2] Benek, J. A., Steger, J., and Dougherty, F., "A Flexible Grid Embedding Technique with Applications to the Euler Equations,” AIAA Paper 1983-1944, 1983. 
[3] Chan, W., Gomez, R., Rogers, S., Buning, P., "Best Practices in Overset Grid Generation”, AIAA Paper 20023191, June 2002.

[4] Noack, R.W. and Slotnick, J.P., "A Summary of the 2004 Overset Symposium on Composite Grids and Solution Technology", AIAA Paper 2005-0921, January 2005.

[5] Meakin, R. L., "Object X-Rays for Cutting Holes in Composite Overset Structured Grids," AIAA Paper 20012537, 2001.

[6] Nichols, R.H. and Tramel, R.W., "Applications of a Highly Efficient Numerical Method for Overset-Mesh Moving Body Problems", AIAA Paper 1997-2255, June 1997.

[7] Buning, P.G., Gomez, R.J., and Scallion, W.I., "CFD Approaches for Simulation of Wing-Body Stage Separation," AIAA Paper 2004-4838, August 2004.

[8] Duque, E. P. N., Strawn, R. C., Ahmad, J. and Biswas, R., "An Overset Grid Navier-Stokes/Kirchhoff-Surface Method for Rotorcraft Aeroacoustic Predictions," AIAA Paper 1996-0152, January 1996.

[9] Lohner, R., Sharov, D., Luo, H., and Ramaurti, R., "Overlapping Unstructured Grids”, AIAA Paper 2001-0439, January, 2001.

[10] Togashi, F., Nakahashi, K., Ito, Y., Iwamia, T. and Shimbo, Y., "Flow Simulation of NAL Experimental Supersonic Airplane/Booster Separation Using Overset Unstructured Grids," Computers \& Fluids, Vol. 30, Issue 6, July 2001, pp. 673-688.

[11] Madrane, A., Raichle, A., and Stuermer, A., "Parallel Implementation of a Dynamic Unstructured Chimera Method in the DLR Finite Volume TAU-Code," 12th Annual Conference of the CFD Society of Canada, Ottawa, Ontario, Canada, 2004, pp. 524-534.

[12] Noack, R.W., "DiRTlib: A Library to Add an Overset Capability to Your Flow Solver," AIAA Paper 20055116, June 2005, 17th AIAA Computational Fluid Dynamics Conference, Toronto, Ontario, Canada.

[13] Noack, R.W., "SUGGAR: A General Capability for Moving Body Overset Grid Assembly," AIAA Paper 20055117, June 2005, 17th AIAA Computational Fluid Dynamics Conference, Toronto, Ontario, Canada.

[14] Noack, R. W. and Kadanthot, T., "An Octree based Overset Grid Hole Cutting Method," Proceedings of 8th International Conference On Numerical Grid Generation in Computational Field Simulations, Honolulu, HI, 2002, pp. 783-792.

[15] Noack, R. W. "Resolution Appropriate Overset Grid Assembly for Structured and Unstructured Grids," AIAA Paper 2003-4123, 16th AIAA Computational Fluid Dynamic Conference, Orlando, FL, 2003.

[16] Frink, N. T., "Upwind Scheme for Solving the Euler Equations on Unstructured Tetrahedral Meshes," AIAA Journal, Vol., No. 1, January 1992, pp. 70-77.

[17] Frink, N. T., "Tetrahedral Unstructured Navier-Stokes Method for Turbulent Flows," AIAA Journal, Vol. 36, No. 11, November 1998, pp. 1975-1982.

[18] Pandya, M.J., Frink, N.T., Abdol-Hamid, K.S., and Chung, J.J., "Recent Enhancements to USM3D Unstructured Flow Solver for Unsteady Flows", AIAA Paper 2004-5201, August 16-19, 2004.

[19] Samareh, J., "GridTool: A surface modeling and grid generation tool," Proceedings of the Workshop on Surface Modeling, Grid Generation, and Related Issues in CFD Solutions," NASA CP-3291, 9-11 May, 1995.

[20] Pirzadeh, S., "Structured Background Grids for Generation of Unstructured Grids by Advancing Front Method," AIAA Journal, Vol. 31, No. 2, February 1993, pp. 257-265.

[21] Pirzadeh, S., "Unstructured Viscous Grid Generation by Advancing-Layers Method," AIAA Journal, Vol. 32, No. 8, August 1994, pp. 1735-1737.

[22] Roe, P., "Characteristic Based Schemes for the Euler Equations," Annual Review of Fluid Mechanics, Vol. 18, 1986, pp. 337-365.

[23] Frink, N. T., "Recent Progress Toward a Three-Dimensional Unstructured Navier-Stokes Flow Solver," AIAA Paper 1994-0061, January 1994.

[24] Anderson, W.; and Bonhaus D., "An Implicit Upwind Algorithm for Computing Turbulent Flows on Unstructured grids," Computers Fluids, Vol. 23, No. 1, 1994, pp. 1-21.

[25] Spalart P., and Allmaras S. A., "One-Equation Turbulence Model for Aerodynamic Flows," AIAA Paper 19920439, January 1992.

[26] Jones,W. P., and Launder, B. E., "The Prediction of Laminarization With a Two-Equation Model of Turbulence," Int. J. Heat \& Mass Transf., Vol. 15, No. 2, February 1972, pp. 301-314.

[27] Sarkar, S., Erlebacher, G., Hussaini, M. Y., and Kreiss, H. O., "The Analysis and Modeling of Dilatational Terms in Compressible Turbulence," J. Fluid Mech., Vol. 227, June 1991, pp. 473-495. 
[28] Menter, F.R., "Improved Two-Equation k-omega Turbulence Models for Aerodynamic Flows", NASA TM103975, October 1992.

[29] Abdol-Hamid, K. S., Frink, N. T., Deere, K. A., and Pandya, M.J., "Propulsion Simulations Using Advanced Turbulence Models with the Unstructured-Grid CFD Tool, TetrUSS," AIAA Paper 2004-0714, January 2004.

[30] Girimaji, S.S., "Fully-Explicit and Self-Consistent Algebraic Reynolds Stress Model," ICAS Report 95-82, 1995.

[31] Shih, T-H, Zhu, J., and Lumley, J.L., “A New Reynolds Stress Algebraic Model,” NASA TM-166614, ICOMP 94-8, 1994.

[32] Frink, N.T., Bonhaus, D.L., Vatsa, V.N., Bauer, S.X.S, Tinetti, A.F., "A Boundary Condition for Simulation of Flow Over Porous Surfaces", Journal of Aircraft, Vol. 40, No. 4, July-August 2003, pp. 692-698.

[33] Karypis, G. and Kumar, V., "Metis: A Software Package for Partitioning Unstructured Graphs, Partitioning Meshes, and Computing Fill-Reduced Orderings of Sparse Matrices,", Version 3.0.3, Univ. of Minnesota, November 1997.

[34] Equations, Tables and Charts for Compressible Flow, NACA Report 1135, Avail. AMTEC Engineering Inc., Bellevue, WA 98004.

[35] Heim, E.R., “CFD Wing/Pylon/Finned Store Mutual Interference Wind Tunnel Experiment," Arnold Engineering Development Center, AEDC-TSR-91-P4, January 1991.

[36] Parikh, P., Pirzadeh, S., and Frink, N. T.: "Unstructured Grid Solutions to a Wing/Pylon/Store Configuration", Journal of Aircraft, Vol. 31, No. 6, November-December, 1994, pp. 1291-1296.

[37] Spalart P., and Allmaras S. A., “One-equation turbulence model for aerodynamic flows," AIAA Paper 19920439, January 1992.

[38] Landon, R., "Data Set 3 NACA 0012 Oscillatory and Transient Pitching," AGARD Report 702, AGARD, January 1982. 


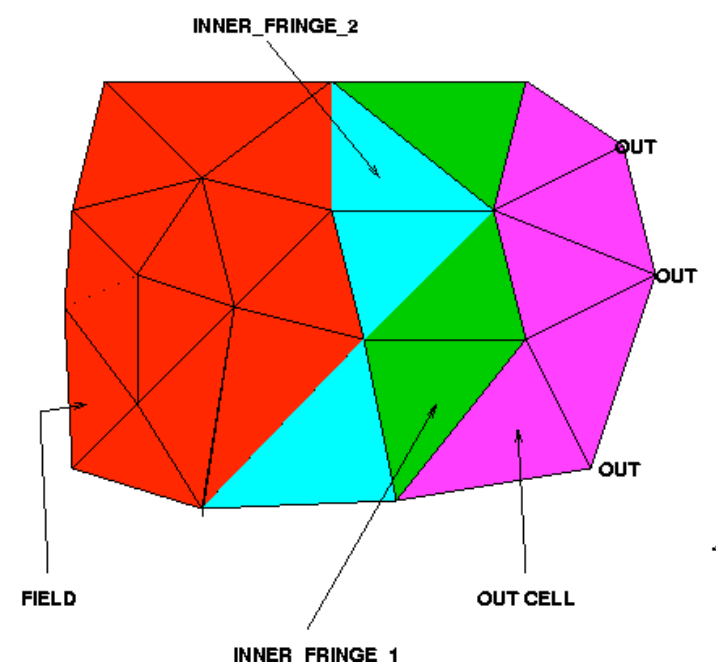

(a) standard fringe-layer marking

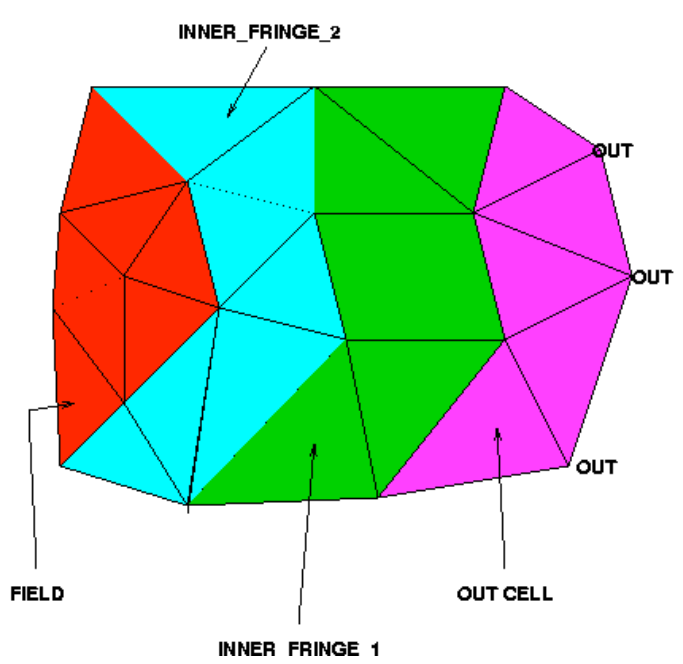

(b) modified fringe-layer marking for USM3D

Figure 1. SUGGAR fringe cell implementation for USM3D.

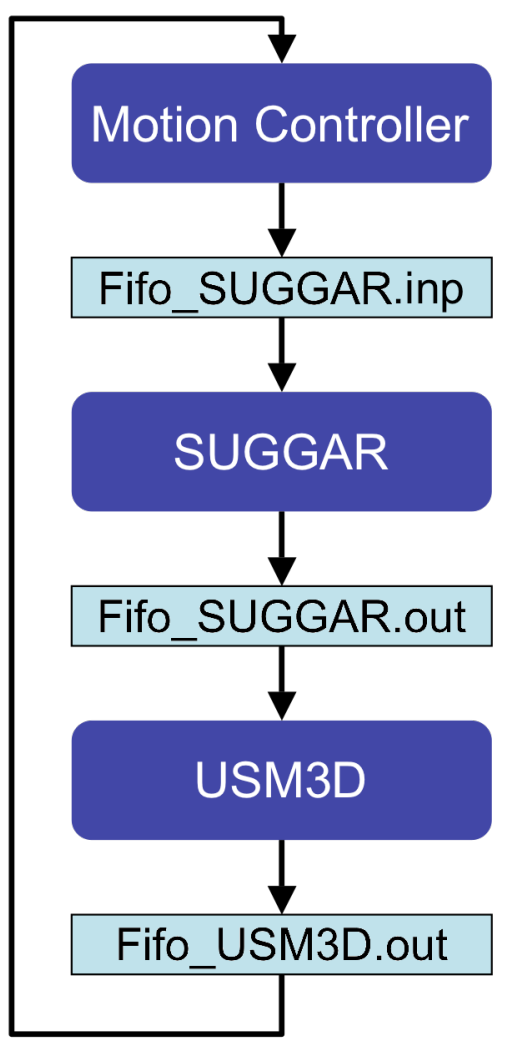

Python script for prescribing grid motion

Grid assembly: hole cutting, donor/receptor connectivity, etc

Several calls to DiRTlib routines

Solver "sees" a single composite grid

Figure 2. Flowchart of overset prescribed-motion moving grid coupling with USM3D flow solver. 


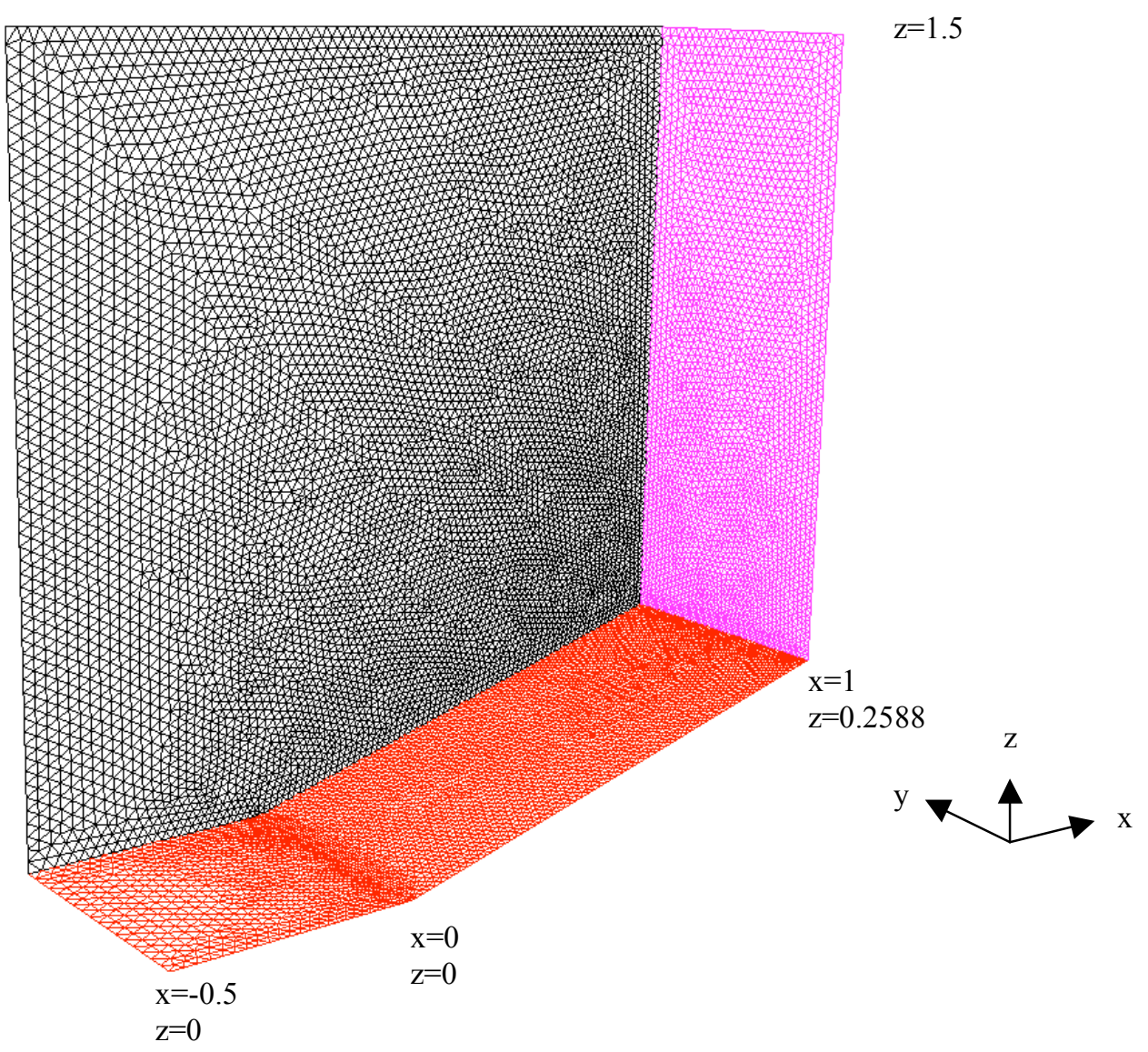

Figure 3. Tetrahedral grid domain for supersonic 15-degree ramp test case with 1,127,529 tetrahedral cells. Inflow and port-side planes removed for clarity.

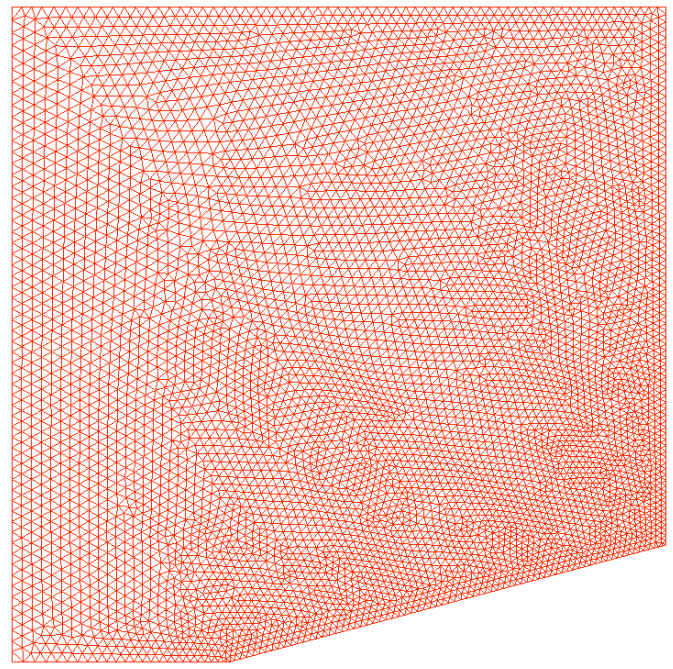

(a) Single grid

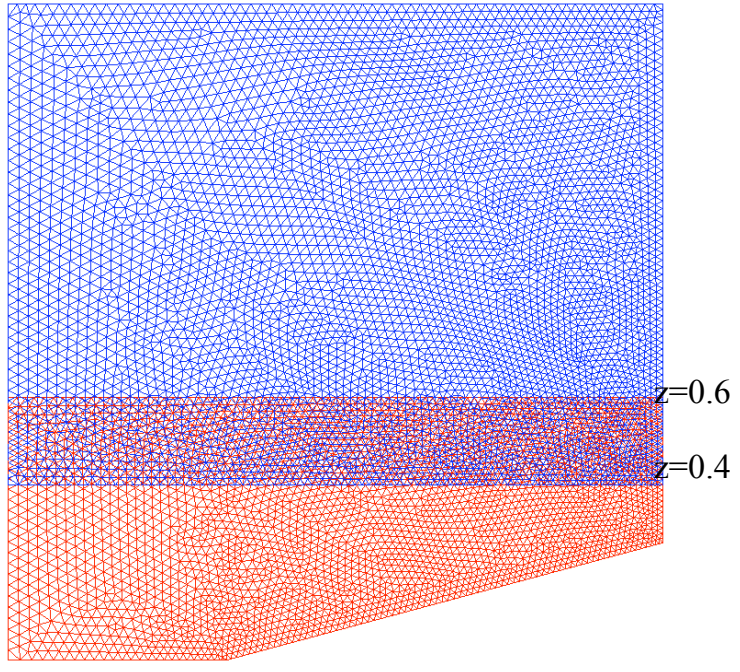

(b) Overset grid

Figure 4. Sidewall triangulations for supersonic 15-degree ramp test case. 


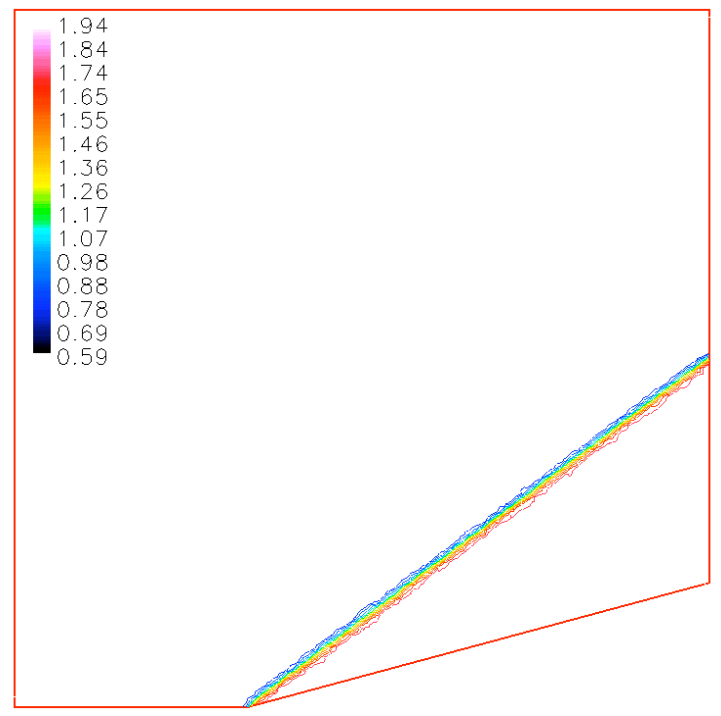

(a) Single grid

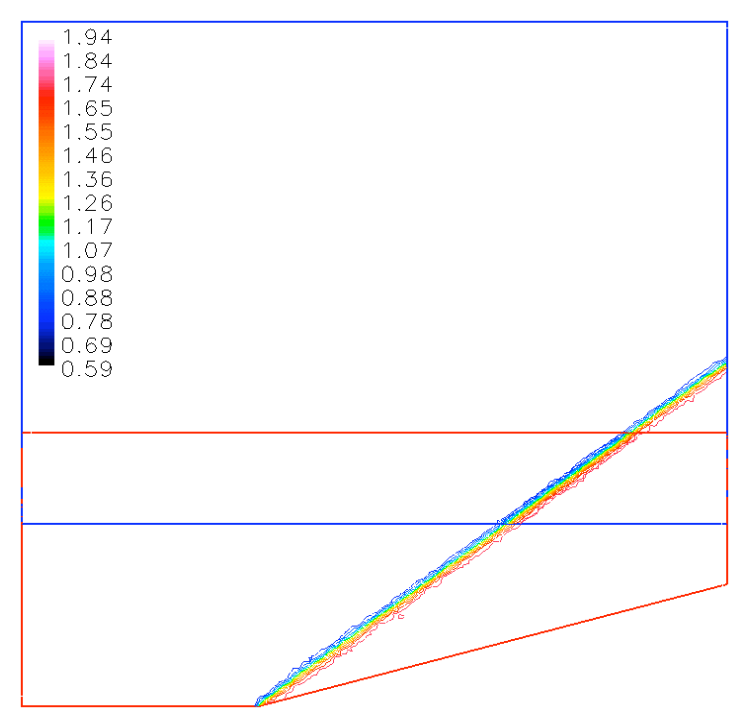

(b) Overset grid

Figure 5. Comparison of single- vs. overset-grid pressure contours on a midspan cutting plane of 15degree ramp test case at Mach 2.5.

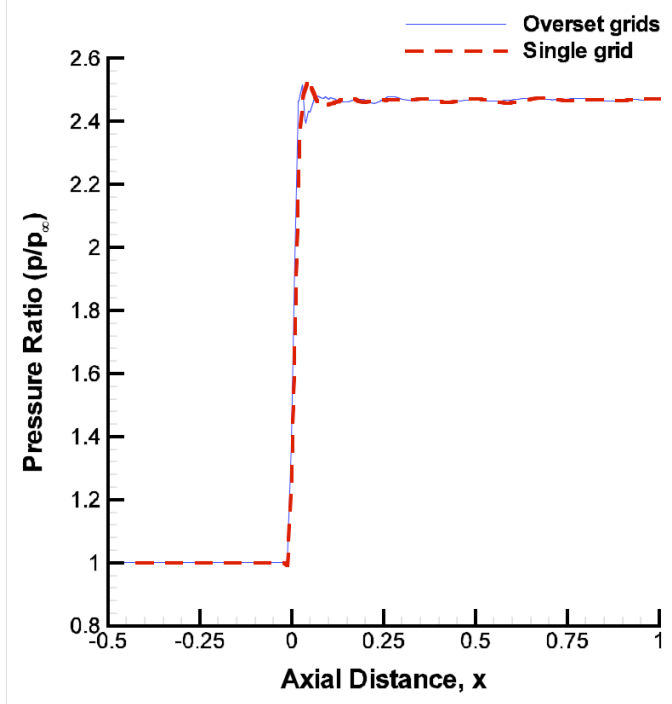

(a) Surface distribution

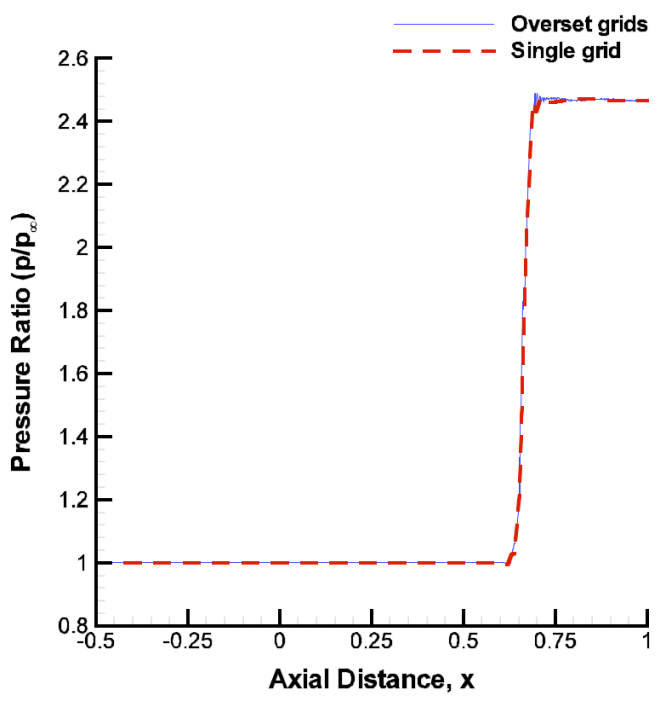

(b) Line through overset, $\mathrm{z}=0.5$

Figure 6. Longitudinal distribution of pressure ratio on surface and on a line passing through center of overset region for 15-degree ramp test case, Mach 2.5 . 


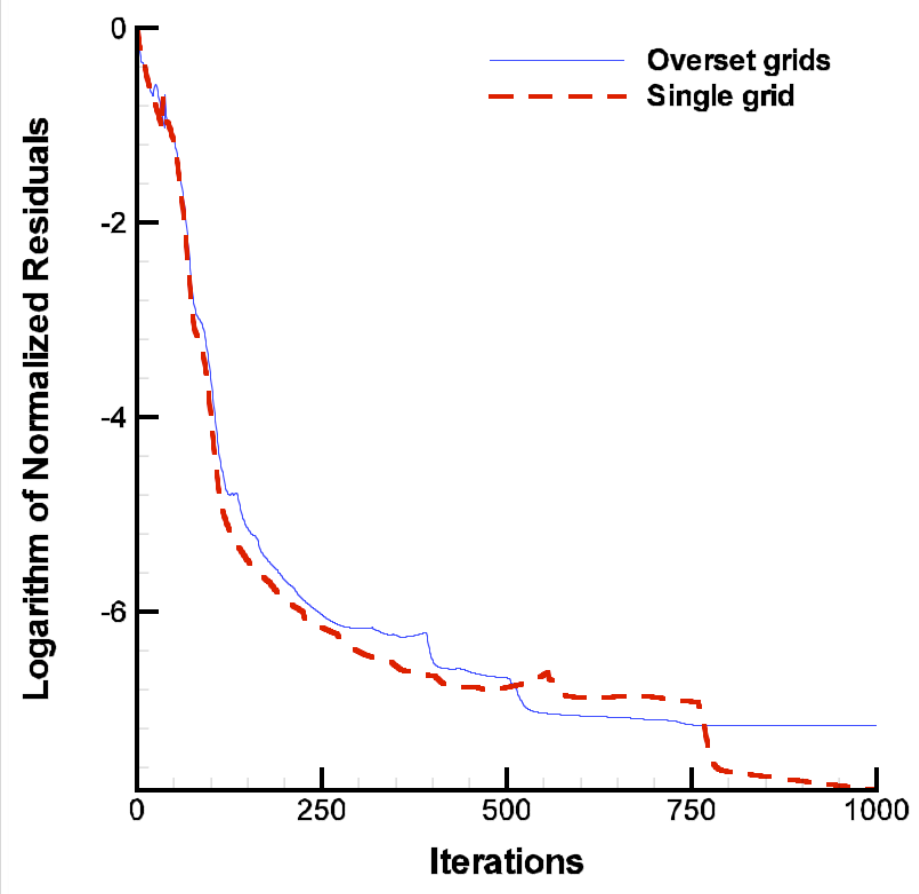

Figure 7. Comparison of USM3D inviscid solution convergence between single- and overset-grid for 15degree ramp at Mach 2.5.

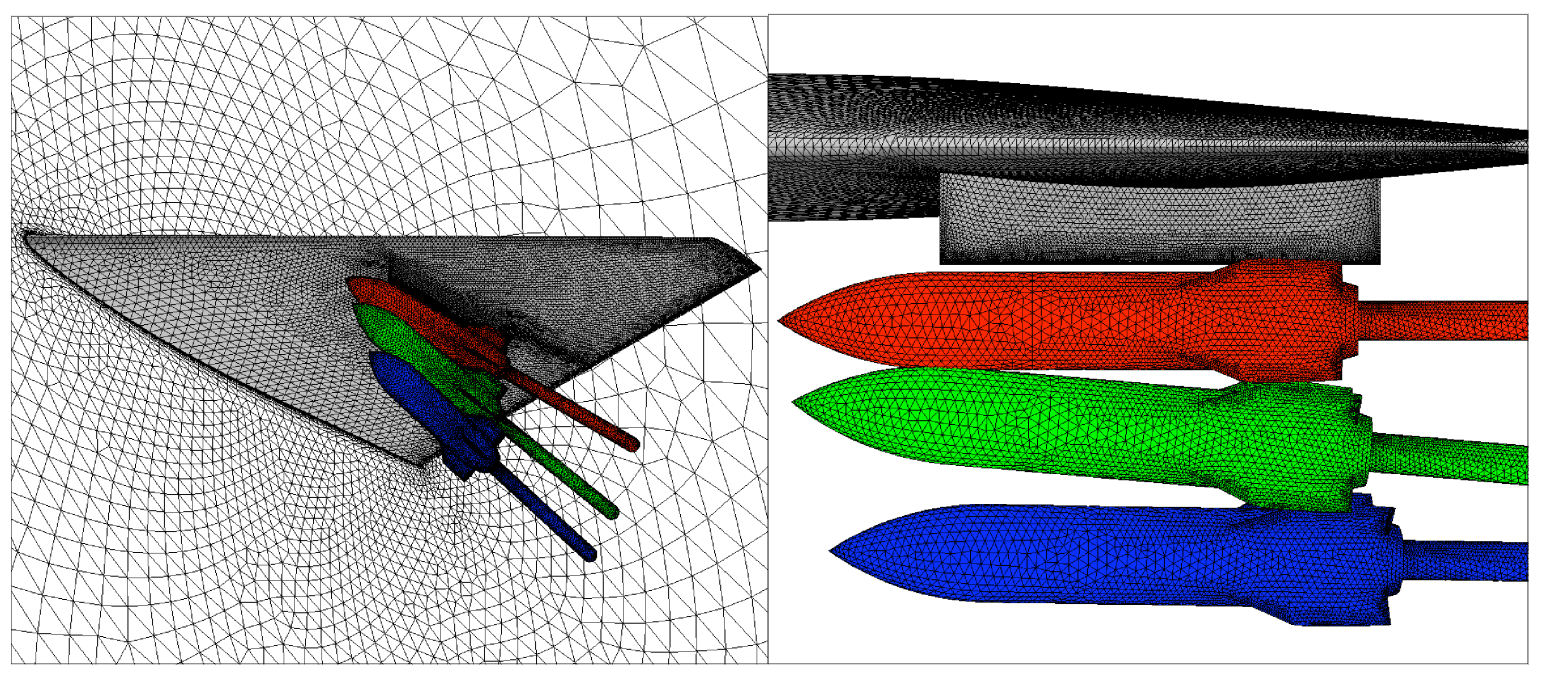

Figure 8. Triangular surface grid on Eglin wing/pylon/store configuration. Store grid shown for Carriage (red), Near (green), and Far (blue) positions. 


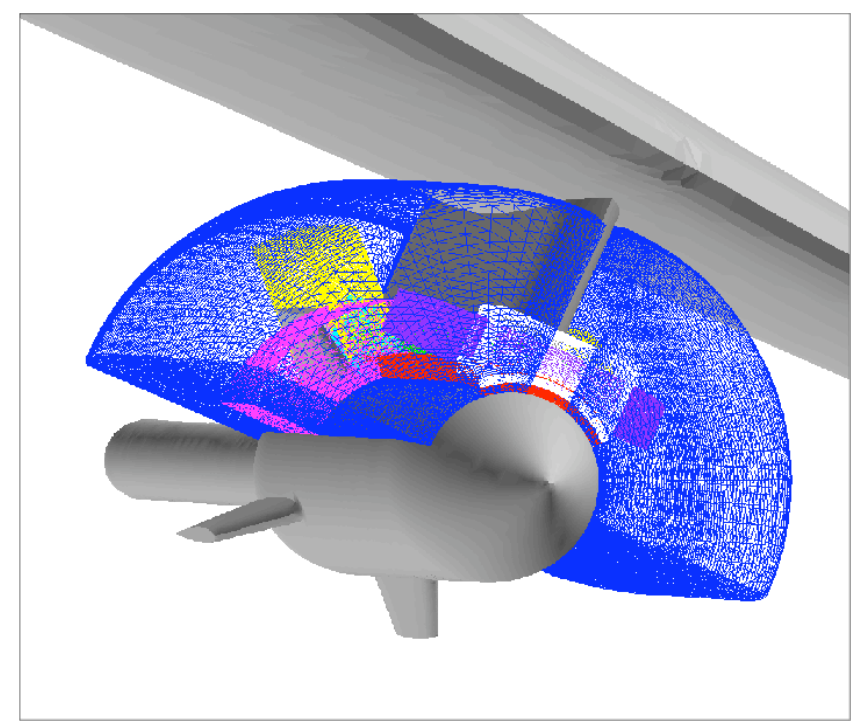

Figure 9. Embedded interface grids (a total of 11 grids) around pylon and store.
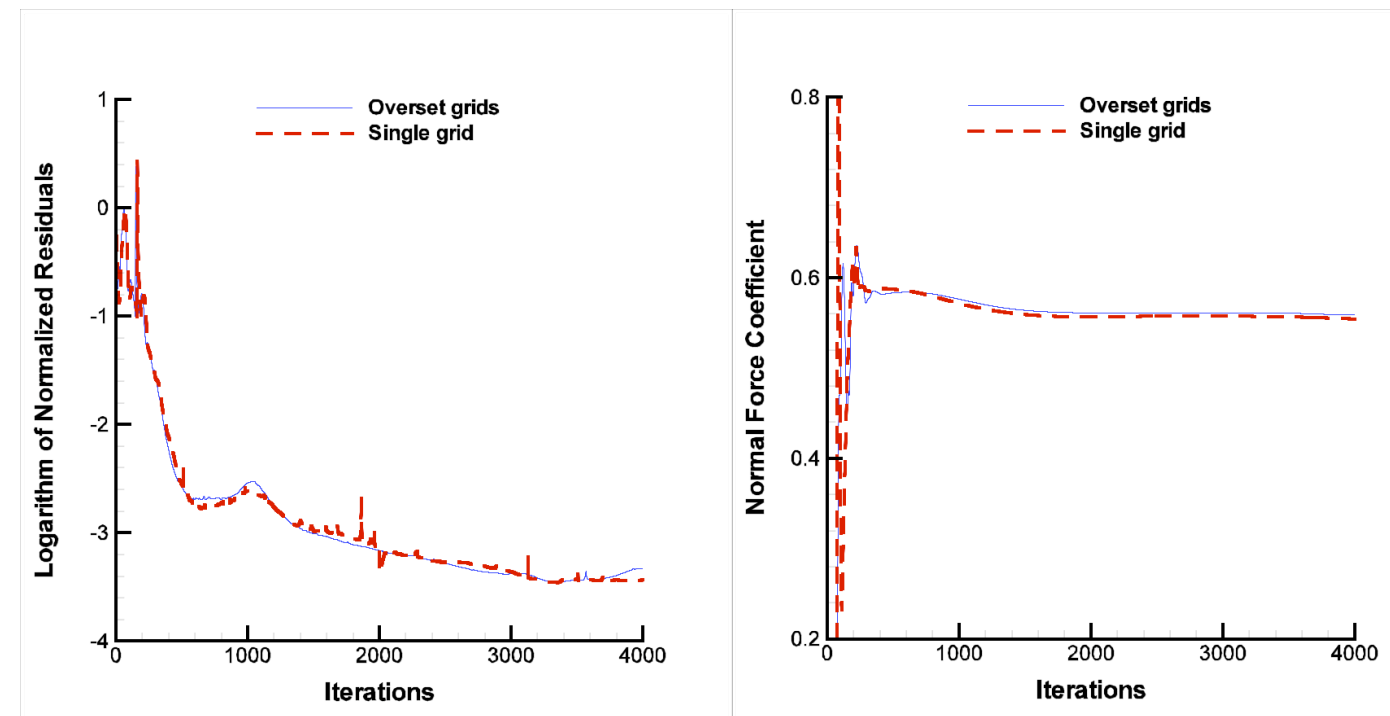

Figure 10. Comparison of overset- vs. single-grid solution convergence for WPS carriage position. Mach $=0.95, \operatorname{Re}=2.56 \times 10^{6} /$ foot, $\mathrm{SA}$ turbulence model. 


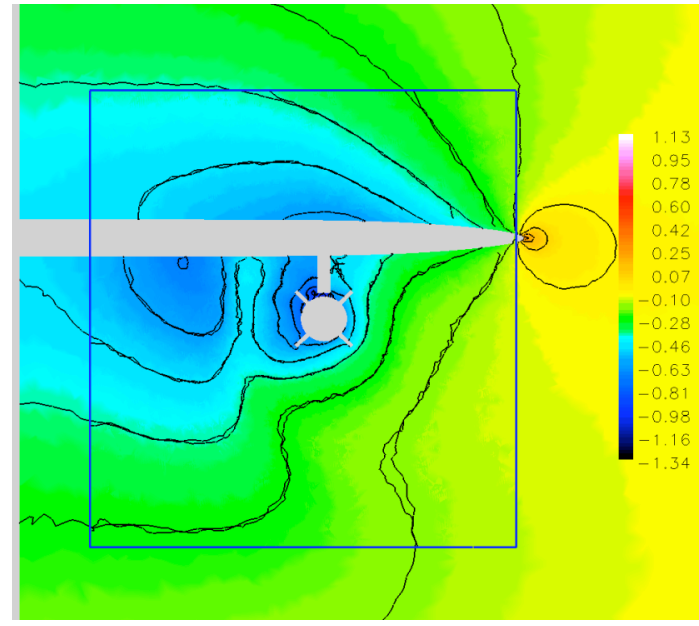

(a) Overset

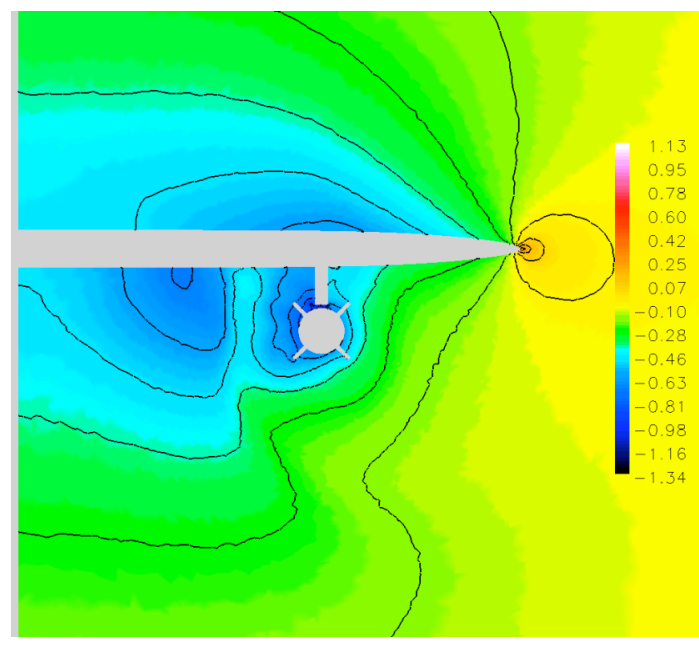

(b) Single

Figure 11. Comparison of overset- vs. single-grid $\mathrm{Cp}$ isobars on longitudinal cutting plane through wing, pylon, and store in carriage position. Overset boundary denoted by inset rectangle. Mach $=0.95$, $\operatorname{Re}=2.56 \times 10^{6} /$ foot, $S A$ turbulence model.

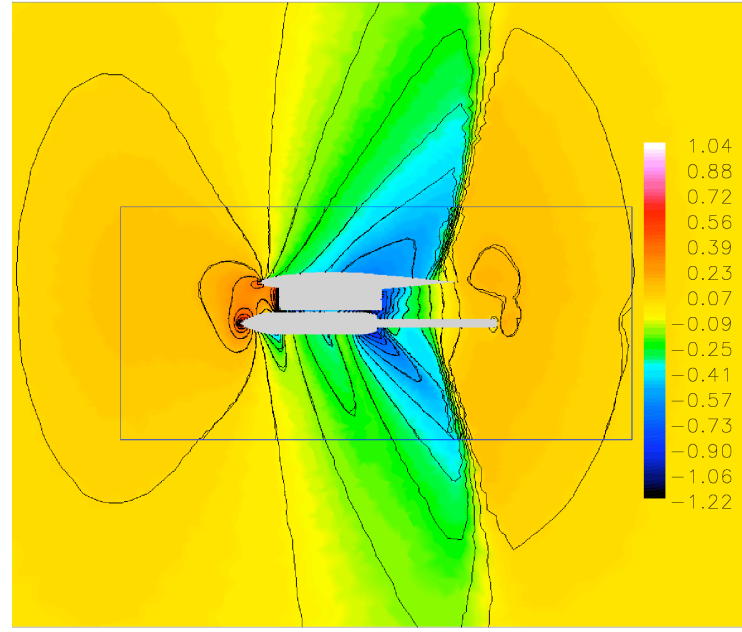

(a) Overset

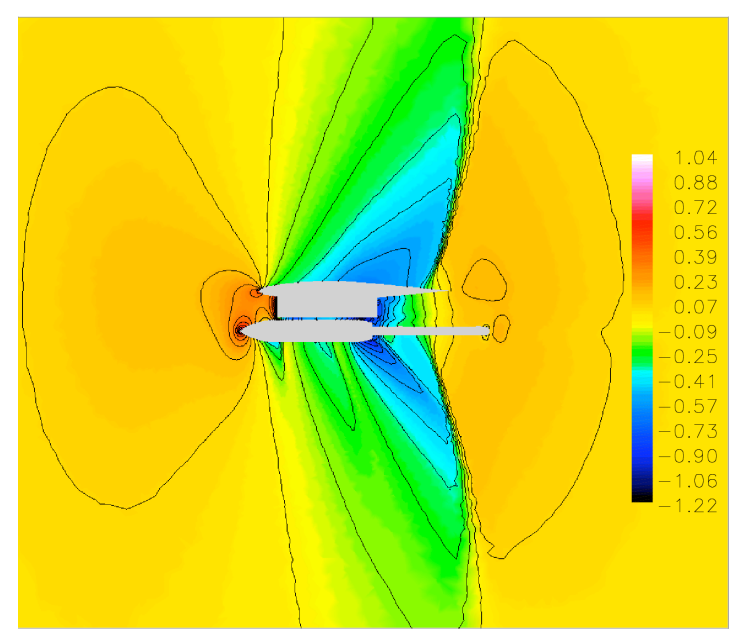

(b) Single

Figure 12. Comparison of overset- vs. single-grid $\mathrm{Cp}$ isobars on streamwise cutting plane through wing, pylon, and store in carriage position. Overset boundary denoted by inset rectangle. Mach $=0.95$, $\operatorname{Re}=\mathbf{2 . 5 6} \times 10^{6} /$ foot, $\mathrm{SA}$ turbulence model. 

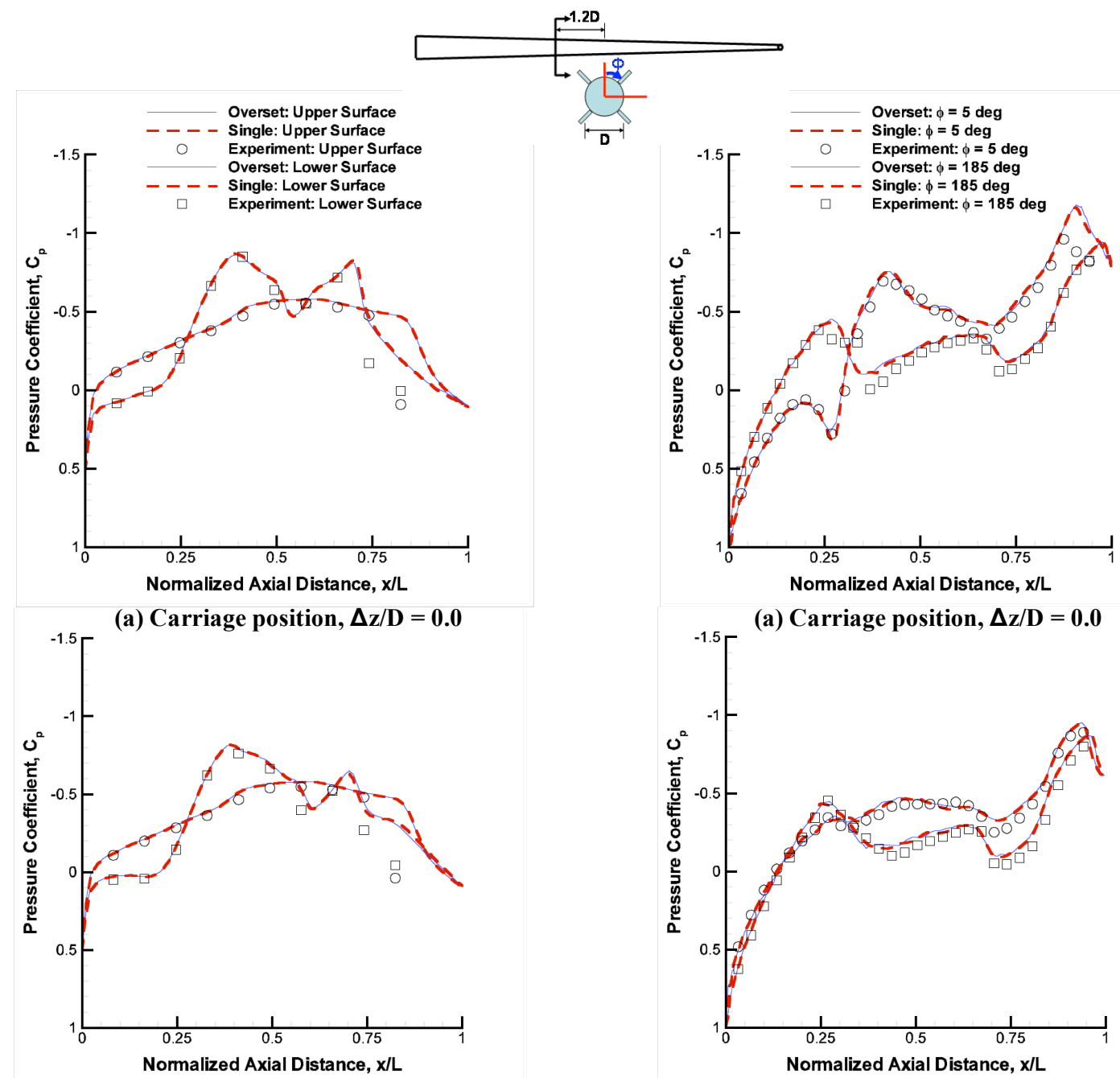

(b) Near position, $\Delta \mathrm{z} / \mathrm{D}=\mathbf{- 1 . 0 6 8}$

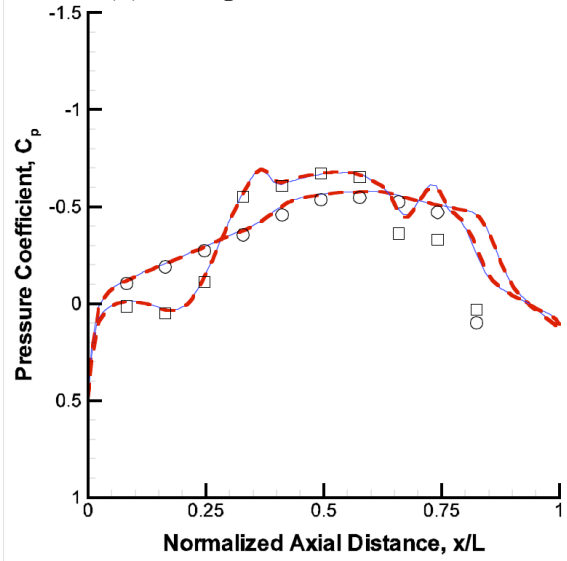

(b) Near position, $\Delta z / D=\mathbf{- 1 . 0 6 8}$

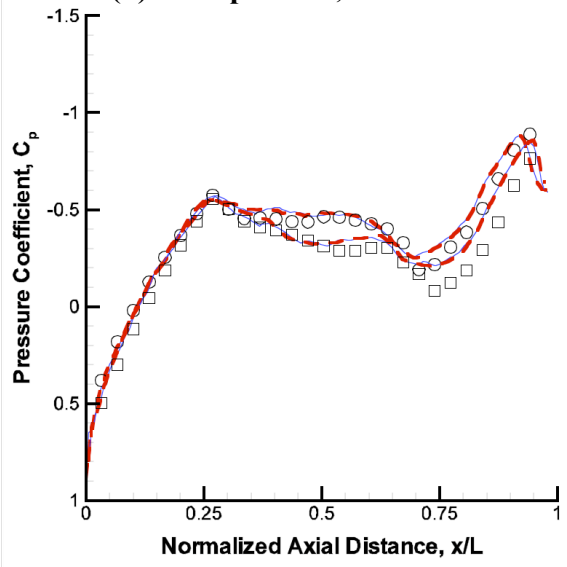

(c) Far position, $\Delta \mathrm{z} / \mathrm{D}=\mathbf{- 2 . 3 8 8}$

Figure 13. WPS chordwise surface pressure comparison at wing station 1.2D inboard of pylon for single vs. overset grid steady-state solutions. Mach $=0.95, \quad \operatorname{Re}=2.56 \times 10^{6} /$ foot, $\mathrm{SA}$ turbulence model.

Figure 14. WPS longitudinal surface pressure comparison along upper and lower store body for single vs. overset grid steady-state solutions. Mach $=0.95, \operatorname{Re}=2.56 \times 10^{6} /$ foot, $\mathrm{SA}$ turbulence model. 


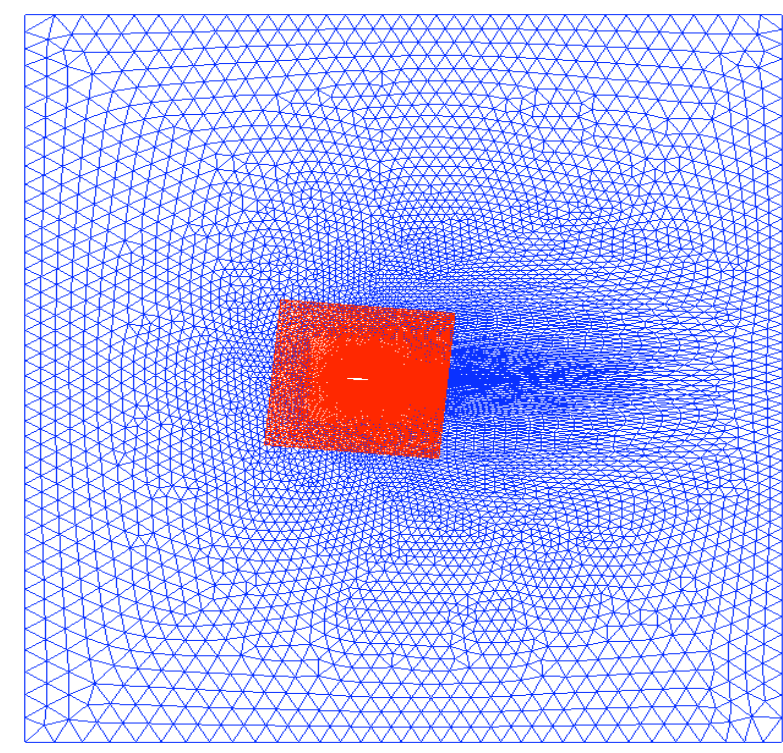

(a) Full sideview

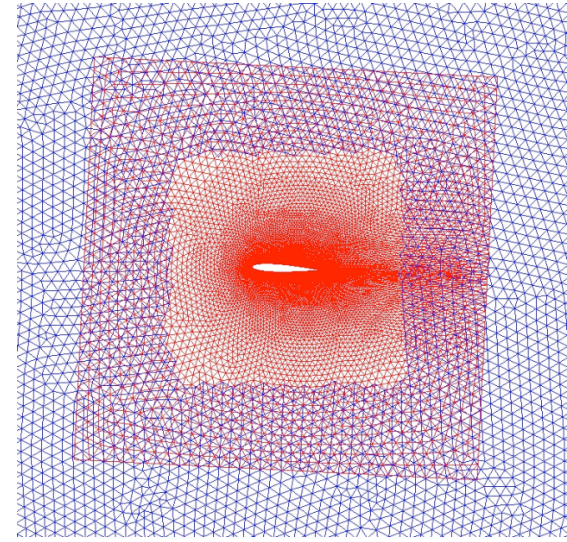

(b) Closeup of overlapped grid

Figure 15. Sideview of quasi-2D channel grid for NACA 0012 oscillating airfoil. Blue is outer box grid with $\mathbf{2 0 1 , 9 7 2}$ cells. Red is airfoil grid with 174,049 cells. Combined composite grid has 376,021 cells.

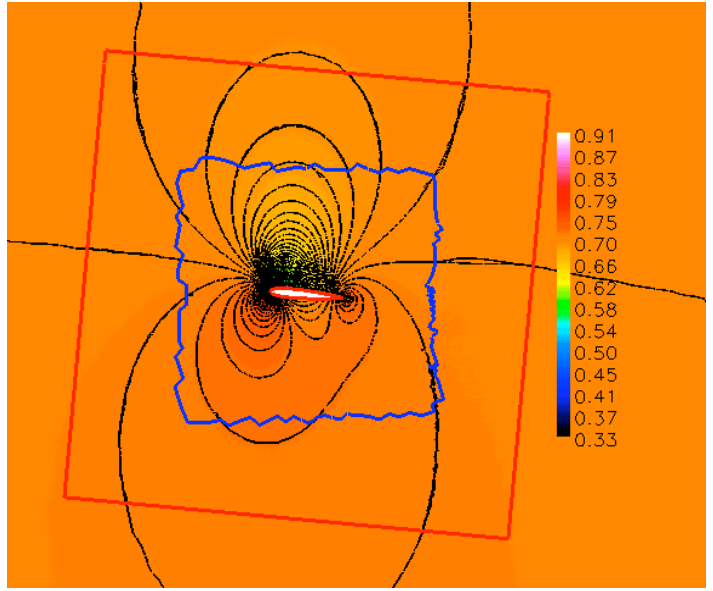

(a) Maximum angle, $\alpha=5.30 \mathrm{deg}$

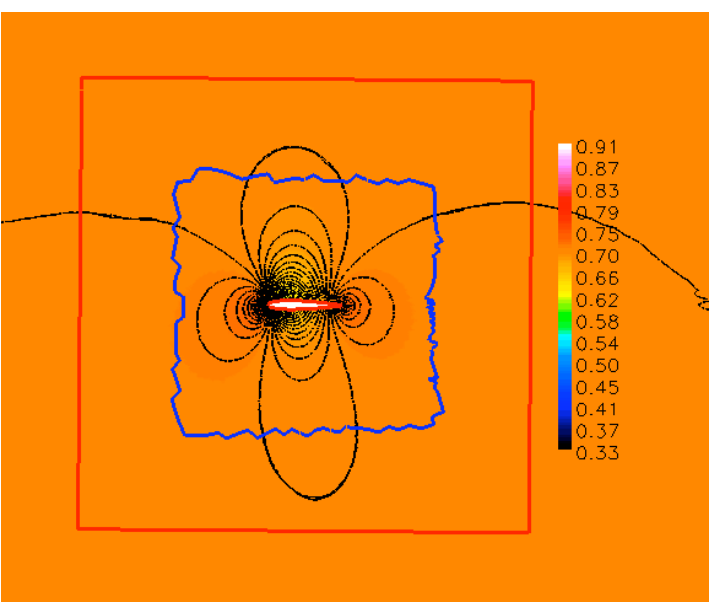

(b) Minimum angle, $\alpha=0.48 \mathrm{deg}$

Figure 16. Effect of overset-grid boundaries on off-body pressure contours for NACA 0012 airfoil in a forced pitching oscillations at $\mathrm{Mach}=0.6, \mathrm{Re}_{\mathrm{c}}=4.2 \times 10^{6} . \alpha(\mathrm{t})=\alpha_{\text {mean }}+\alpha_{\mathrm{ampl}} \sin (2 \pi f \mathrm{t}), \alpha_{\text {mean }}=2.89^{\circ}, \alpha_{\mathrm{ampl}}=$ $2.41^{\circ}, f=50 \mathrm{~Hz}$. 

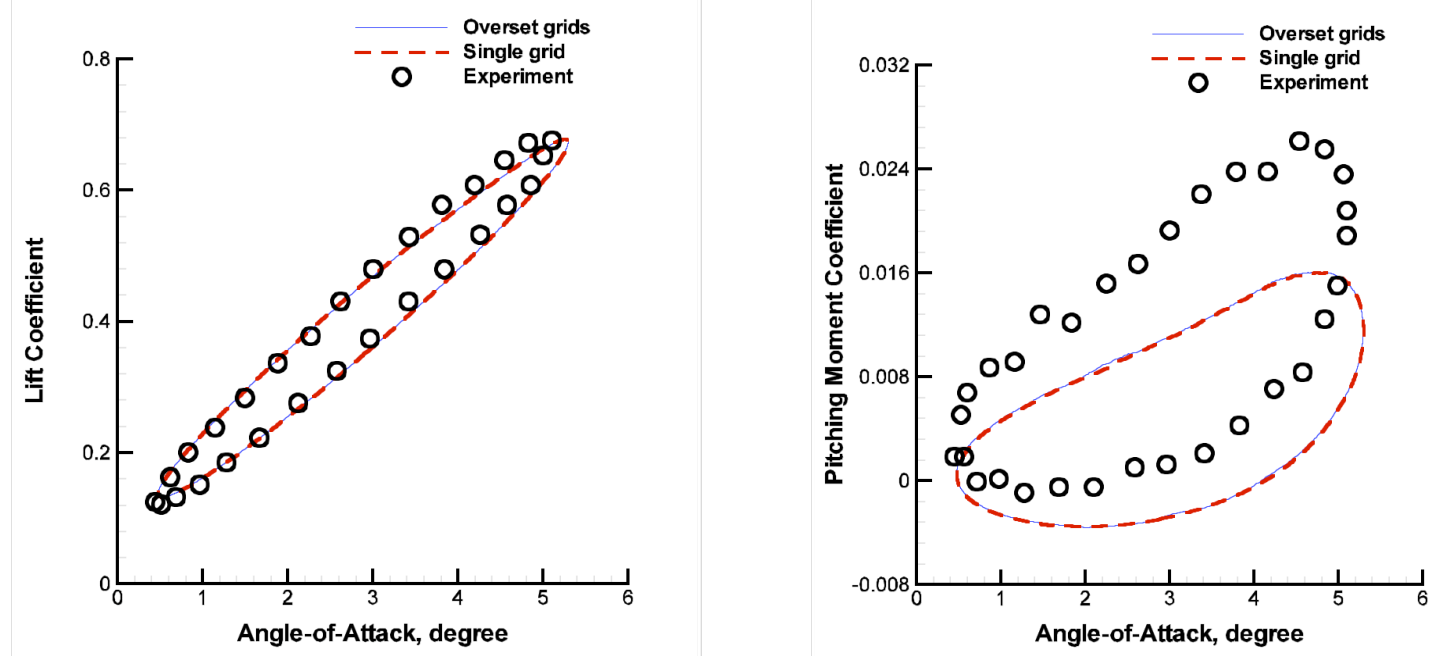

Figure 17. Comparison of single vs. overset grid lift and moment coefficient hysteresis for NACA 0012 airfoil in a forced pitching oscillations at $\mathrm{Mach}=0.6, \mathrm{Re}_{\mathrm{c}}=4.2 \times 10^{6} . \alpha(\mathrm{t})=\alpha_{\text {mean }}+\alpha_{\text {ampl }} \sin (2 \pi f t), \alpha_{\text {mean }}=$ $2.89^{\circ}, \alpha_{\text {ampl }}=2.41^{\circ}, f=50 \mathrm{~Hz}$. 